\title{
Large-Scale Integrated Carbon Nanotube Gas Sensors
}

\author{
Joondong Kim \\ Nano-Mechanical Systems Research Center, Korea Institute of Machinery and Materials (KIMM), Daejeon 305343, Republic of Korea \\ Correspondence should be addressed to Joondong Kim, joonkim@kimm.re.kr
}

Received 16 October 2011; Revised 7 March 2012; Accepted 20 March 2012

Academic Editor: Teng Li

Copyright (C) 2012 Joondong Kim. This is an open access article distributed under the Creative Commons Attribution License, which permits unrestricted use, distribution, and reproduction in any medium, provided the original work is properly cited.

Carbon nanotube (CNT) is a promising one-dimensional nanostructure for various nanoscale electronics. Additionally, nanostructures would provide a significant large surface area at a fixed volume, which is an advantage for high-responsive gas sensors. However, the difficulty in fabrication processes limits the CNT gas sensors for the large-scale production. We review the viable scheme for large-area application including the CNT gas sensor fabrication and reaction mechanism with a practical demonstration.

\section{Introduction}

Due to the excellent and well-known properties of nanoscale materials, intensive research has been performed in various areas. The one-dimensional nanoscale structure of a nanowire or a nanotube is attractive for use in effective cold cathodes [1], field emitters [2], and vacuum microelectronics $[3,4]$. Recently, silicide nanowire has shown the possibility of nanoscale interconnection with low resistance $[5,6]$. Additionally, carbon nanotubes have been applied in various applications such as energy storage devices, sensors [7, 8 ], and actuators. The electrical conductivity of carbon nanotubes (CNTs) is prominent $\left(10^{6} \mathrm{~S} \mathrm{~m}^{-2}\right)$, and thus CNT films also possess a low sheet resistance while holding an excellent optical transmittance in the visible spectrum comparable to that of commercial indium-tin-oxide (ITO); a transparent CNT film heater has been realized [9].

The one-dimensional nanoscale structure of CNT has a large surface area to volume ratio, which is an advantage for maximizing the surface response. Moreover, the radii, which are comparable to the Debye length, offer greater potential in sensing performance, compared to bulk, by showing sensitive changes upon exposure to gas molecules.

CNTs have been intensively investigated for use in gas sensing devices due to their unique physical and chemical properties [10-18]. It has been proven that CNTs present the p-type semiconducting property due to their unique chirality. The absorbing gas molecules can significantly change the conductivity of CNTs by withdrawing and donating electrons $[7,10,19]$. Moreover, the high surfaceto-volume ratio of CNTs provides an advantage in sub-ppm level gas detection. The theoretical concept of using metalnanoparticle functionalized CNTs has been reported and it has been shown that metal nanoparticles act as reactive sites to target gas molecules. A significant change in electrical conductivity is driven by absorbing target molecules [15-20].

This paper reviews the previous reports on CNT-based gas sensors. It discusses the deployment method of CNTs for large-scale applications with a working mechanism.

\section{Fabrication Methods}

2.1. Fabrication of CNTs. Generally, three types of method are used to growth CNTs [14]. The first method is the arc-discharge method, which grows single and multi-walled CNTs in a vacuum system under an inert gas atmospheric condition. In laser ablation, a carbon target ablated by intense laser pulses in a furnace and the formed CNTs are collected on a cold substrate. The chemical vapor deposition method is the most popular technique; it uses a gaseous carbon source resulting in vertical grown CNTs. Moreover, quality CNTs can be produced at a reduced growth temperature under $1000^{\circ} \mathrm{C}$, which compares favorably to the temperature above $3000^{\circ} \mathrm{C}$ of the arc-discharge or the laser ablation processes. Recently, the hydrothermal method has been developed for the formation of crystalline particles or films; 
this method provides more opportunity for the modification of the CNT configuration [15]. Hetero-structured CNT entities, such as CNT-ZnO film [21] and $\mathrm{Fe}_{3} \mathrm{O}_{4}$ nanoscale crystal-treated CNTs [22], have demonstrated the quality heterojunction between CNTs [15].

2.2. Dielectrophoresis. It is an essential process to assign nanostructures at a designated spot for device applications $[5,6]$. Dielectrophoresis (DEP) is a promising approach to align nanostructures at a designated position with high reliability and accessibility. A motion is induced by the polarization effect exerting a force on a dielectric particle under a nonuniform electric field condition. The DEP method was performed to align CNTs by dropping the CNT-containing solution between the electric field applied to metal electrodes.

2.3. Inkjet Printing. Although the benefit of nanomaterials has been clarified in various applications, the assignment of manipulating the nanoscale materials with certainty in practical applications still remained. It is an essential and inevitable process to control the nanomaterials at designated positions. Inkjet printing is the demand-oriented technology by dropping ink droplets when required. The drop-on-demand scheme is realistic and large area available approach of locating functional materials [8]. The inkjet printing method provides the schemes of high sensitive CNT-embedded gas sensor units on a wafer-scale by inkjetting carbon-nanotubecontained solution following the conventional lithographical metal lift-off processes.

\section{Results and Discussion}

3.1. CNT Mats. In the sensor fabrication, a Ti adhesion layer of $5 \mathrm{~nm}$ thick was deposited before a $50 \mathrm{~nm}$ thick Pt coating on an $\mathrm{SiO}_{2}$-coated wafer. Firstly, a CNTs dispersed solution was prepared by ultrasonic vibrating from the CNTs grown substrate, and then the CNT solution was dropped between Pt electrodes under an ac electric field of $10 \mathrm{~V}$ at $10 \mathrm{kHz}$. The CNTs-connected electrodes were observed by field emission scanning electron microscopy (FESEM, FEI Sirion), as shown in Figure 1. No post contact treatment has been performed to reinforce the contact formation between CNTs to Pt electrodes.

The electrical measurement from the as-placed CNTs on Pt electrodes gave a resistance of $64.5 \mathrm{k} \Omega$ swept by Keithley 2400 , as shown in Figure 2. There was no significant contact noisy resistance reported as much as Megohm unit [23], which was supposed to be very small [6].

Figure 3 is the CNT sensor response to $100 \mathrm{ppb} \mathrm{NO}_{2}$ gas. The CNT sensor response $[R]$ was defined as the ratio $R=$ $\left(R_{i}-R_{r}\right) / R_{i}$, where $R_{i}$ and $R_{r}$ represent the initial resistance and the reacted resistance to $\mathrm{NO}_{2}$ gas, respectively. Two different magnitude voltages of 0.5 and $2.0 \mathrm{~V}$ were applied and four various processing steps were taken to investigate the CNT sensor performance. The first process (I) was the sensor response to $\mathrm{NO}_{2}$ for $50 \mathrm{~min}$ showing different responses by changing the applied voltage. A higher input voltage of $2.0 \mathrm{~V}$ enhanced the sensing response compared to that of $0.5 \mathrm{~V}$

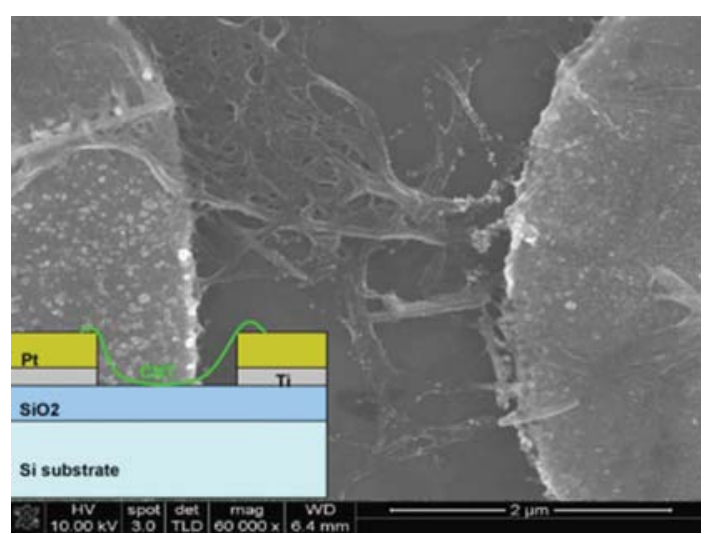

FIgure 1: A SEM image of the as-deposited CNTs on Pt electrodes by a DEP method. Inset shows a schematic cross-sectional view [7].

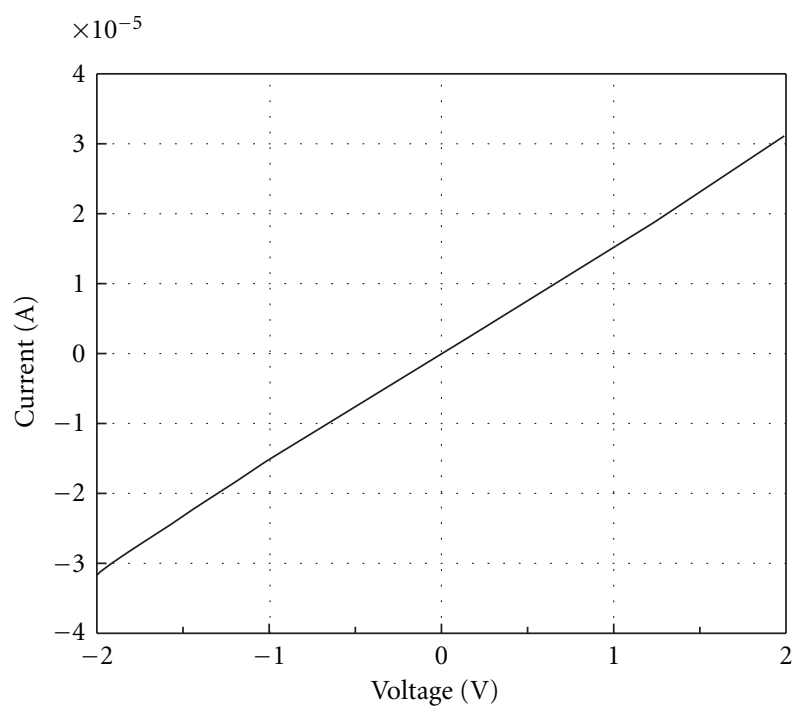

Figure 2: Electrical measurement of the as-deposited CNTs on Pt electrodes [7].

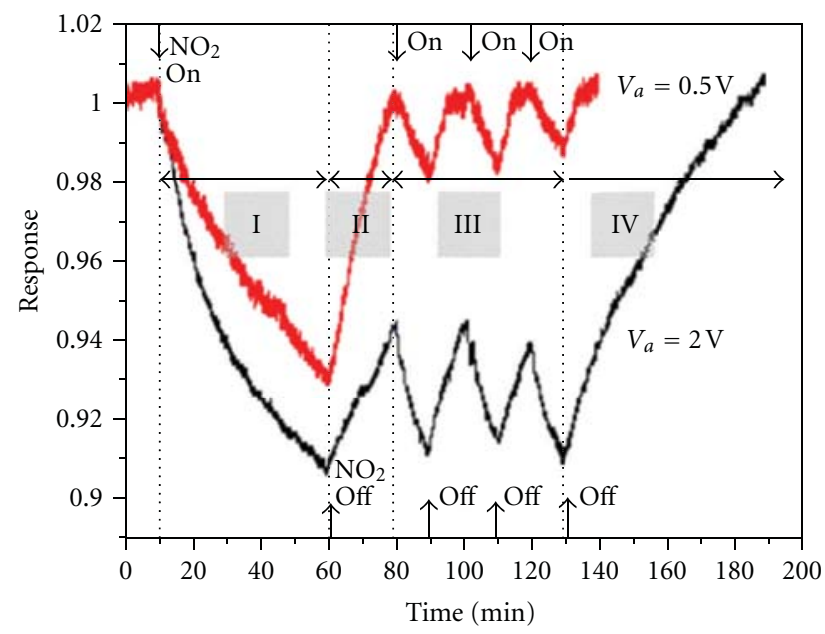

Figure 3: The time-dependent sensing response to $100 \mathrm{ppb} \mathrm{NO}_{2}$ of the CNT sensor at room temperature [7]. 


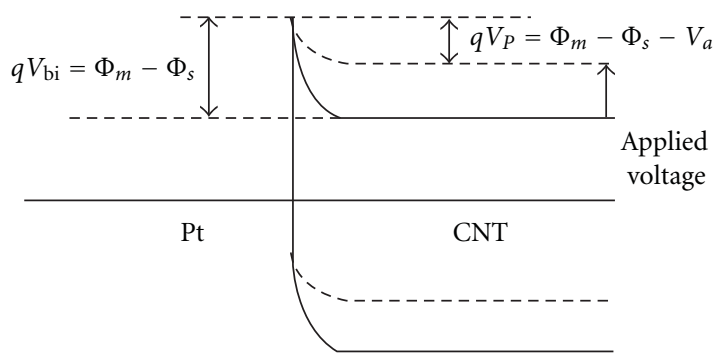

FIgure 4: The band diagram of the Pt and CNT junction [7].

applied case. The second process (II) was to recover the initial resistance by UV illumination for a limited time span of $20 \mathrm{~min}$. The third process (III) was performed to investigate the transient $\mathrm{NO}_{2}$ responses and UV light recovery steps for 10 min time spans. The last step (IV) was performed for fully recovering the initial resistance by longer time duration of 60 min, especially for the $2.0 \mathrm{~V}$ case.

The UV-illuminated recovery seems to be very effective; otherwise, it takes more than $15 \mathrm{~h}$. The UV illumination decreases the desorption-energy barrier to facilitate $\mathrm{NO}_{2}$ desorption from the CNTs. As clearly shown in the figure, the larger voltage input provided higher response in the first region (I). More details will be discussed in the later part. In the second step (II), the case of a lower voltage of $0.5 \mathrm{~V}$ was fully recovered for $20 \mathrm{~min}$, while the higher voltage of $2.0 \mathrm{~V}$ was partially recovered. For the transient responses (III), the $\mathrm{NO}_{2}$ sensing and recovery were repeatedly achieved in a $10 \mathrm{~min}$ time span. A long recovery time of $60 \mathrm{~min}$ was needed to recover the initial resistance for the $2.0 \mathrm{~V}$ input case denoted as region IV. It is remarkable that the applied voltage controls the sensor responses. The gas sensing response was improved by increasing the applied voltage. However, the higher applied voltage case required a longer recovery time of $60 \mathrm{~min}$, resulting from the increased transferring carriers from CNTs to electrodes. This can be explained by changes in the Schottky junction formation between CNTs and Pt electrodes, where the work function is 4.5 and $5.65 \mathrm{eV}$, respectively. A corresponding schematic of the Schottky formation of Pt and CNT contacts is shown in Figure 4.

There exists a potential barrier for the electron transferring from CNTs to the metal. The band bending or built-in potential $\left(V_{\mathrm{bi}}\right)$ of the Pt and CNT connection is given by

$$
V_{\mathrm{bi}}=\Phi_{m}-\Phi_{s}
$$

The initial built-in potential is equal to $1.15 \mathrm{eV}$ from the equation. Under the bias $\left(V_{a}\right)$, the carrier transferring from CNTs to Pt is enhanced due to the reduced potential barrier as given by

$$
V_{P}=\Phi_{m}-\Phi_{s}-V_{a} .
$$

The easier electron transferring by the forward bias-induced barrier lowering may enhance the gas reacting response, which also explains the longer recovery time for the higher applied voltage case. By increasing the number of transferring electrons from CNTs to the Pt electrode by increasing

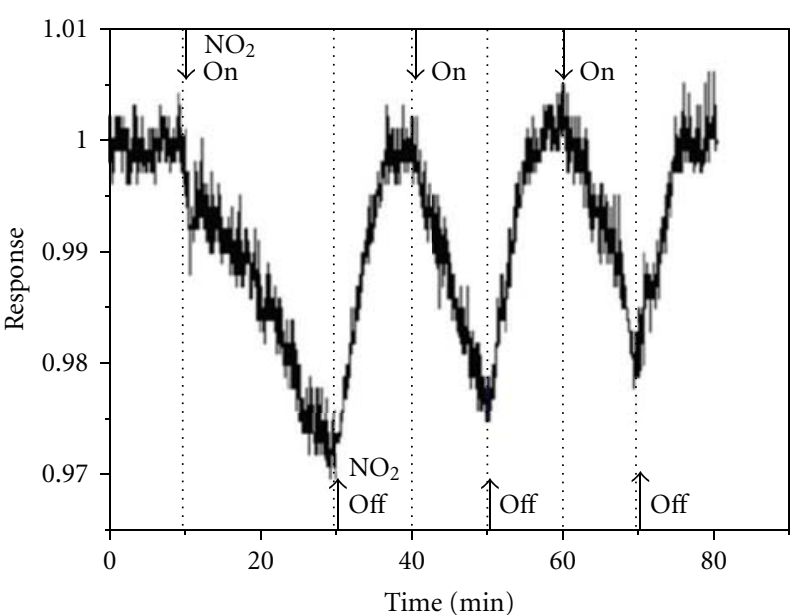

Figure 5: The time-dependent sensing response to $50 \mathrm{ppb} \mathrm{NO}_{2}$ of the CNT sensor at room temperature [7].

the input voltage, more electrons might be captured by $\mathrm{NO}_{2}$ molecules resulting in the need of a longer recovery time.

Figure 5 shows the sensor response at an $\mathrm{NO}_{2}$ concentration of $50 \mathrm{ppb}$. The bias voltage of $2 \mathrm{~V}$ was applied, and the experimental conditions and processes were given similar to the case of $100 \mathrm{ppb} \mathrm{NO}_{2}$. The $\mathrm{CNT}$ sensor detected the $50 \mathrm{ppb}$ level of $\mathrm{NO}_{2}$ successfully and repeatedly. Due to the low $\mathrm{NO}_{2}$ concentration, the first gas reaction was performed in $20 \mathrm{~min}$, and then the time was spanned as $10 \mathrm{~min}$. This CNT sensor operating at room temperature and atmospheric pressure showed highly sensitive and reliable performances. It is an advantage in fabrication to reduce the processing steps and cost.

3.2. Pd-Decorated CNTs. In preparation of the CNT containing solution, commercial arc discharge synthesized singlewall CNTs (Iljin nanotech, ASP-100) were dispersed in a dimethylformamide (DMF) solution for hydrophilic condition to debundle and stabilize the CNT dispersion in solution followed by centrifugation for $30 \mathrm{~min}$ to remove residuals. The supernatant was decanted after the sonication process. The concentration of the CNT solution was approximately $20 \mu \mathrm{g} \mathrm{mL}^{-1}$. To produce the Pd nanoparticle decoration on CNTs, a palladium(II) chloride (Sigma Aldrich) solution was mixed with the bare CNT solution at a volume ratio of $3: 10$. The CNT-containing solution of $0.2 \mu \mathrm{L}$ was dropped between the Pt electrodes under an ac electric field of $10 V_{\text {p-p }}$ (peakto-peak) at $1 \mathrm{kHz}$.

Figure 6 showed the Pd-decorated CNTs on the Pt metal electrodes. The interdigitated Pt electrodes having 10 fingers with a $2 \mu \mathrm{m}$ gap were presented in Figure 6(a). The image of a single finger was presented in Figure 6(b). The enlarged images were shown in Figures 6(c) and 6(d). The Pt nanoparticle-decorated CNTs were clearly observed. Thermal treatment was performed by a rapid thermal process (RTP 2000, SNTEK), which stabilized the contact between the CNTs and Pt metal electrodes by lowering the contact resistance. Raman spectroscopy was used to investigate the 


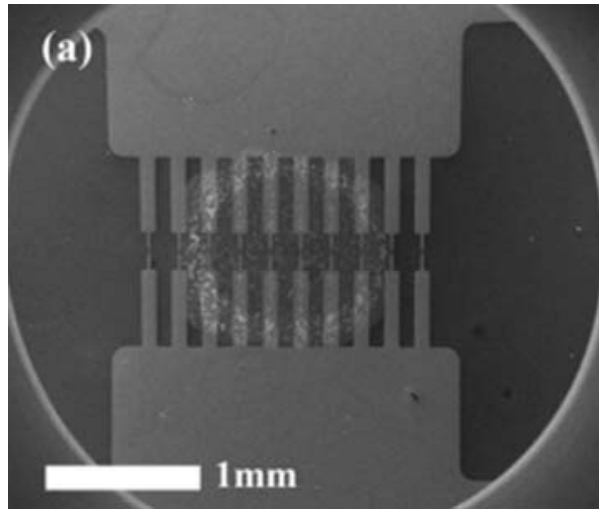

(a)

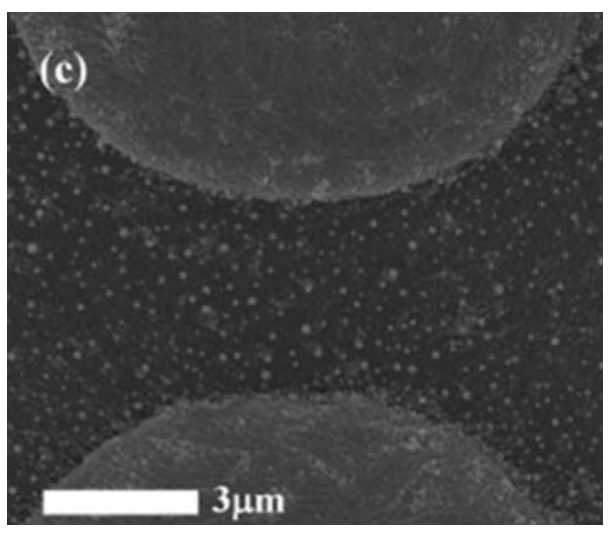

(c)

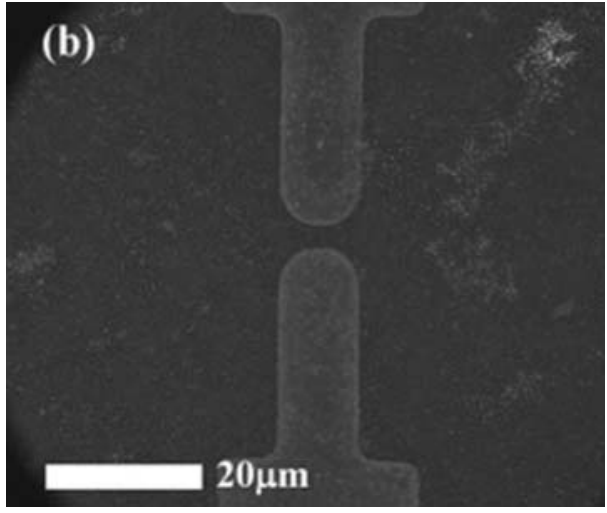

(b)

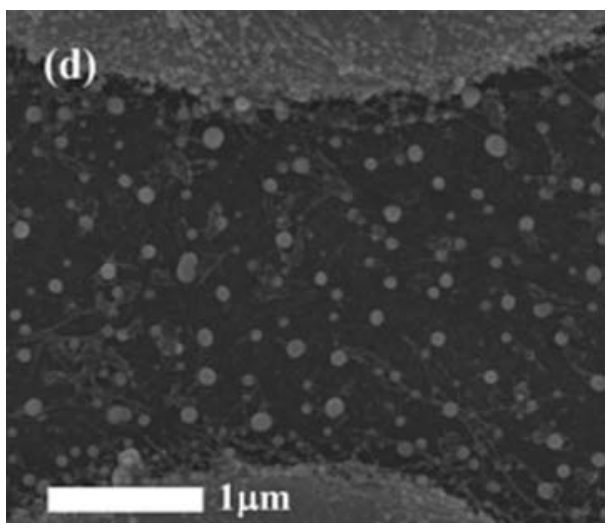

(d)

Figure 6: SEM images of Pd-CNTs between Pt electrodes assembled by the DEP method. (a) Ten finger Pt electrodes, (b) a single finger, (c) Pd-CNTs aligned Pt electrodes, and (d) an enlarged image of (c) [24].

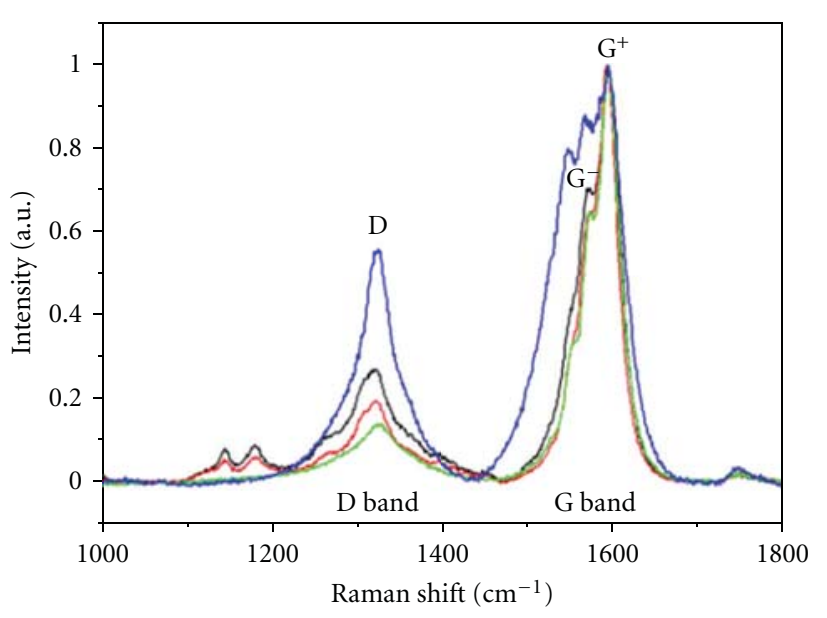

As deposited $\mathrm{D} / \mathrm{G}^{+}=0.267$
$300^{\circ} \mathrm{C}$ annealed $\mathrm{D} / \mathrm{G}^{+}=0.192$
$450^{\circ} \mathrm{C}$ annealed $\mathrm{D} / \mathrm{G}^{+}=0.139$
$-600^{\circ} \mathrm{C}$ annealed $\mathrm{D} / \mathrm{G}^{+}=0.552$

Figure 7: Raman signals of D and G spectra at $632.8 \mathrm{~nm}$ excitation showing the defect ratios from the Pd-CNTs treated at different temperatures [24]. defect level of Pd-CNT samples. The Raman spectra were observed at $632.8 \mathrm{~nm}$ excitation $(1.96 \mathrm{eV})$ on the dropped and dried CNT solution on a silicon substrate. Three different types of samples were thermally treated at 300, 450, and $600^{\circ} \mathrm{C}$ for $1 \mathrm{~min}$ in an $\mathrm{N}_{2}$ environment. The as-deposited sample was also investigated.

Figure 7 depicts the $G$ band Raman peaks obtained at $1592 \mathrm{~cm}^{-1}\left(\mathrm{G}^{+}\right)$and $1572 \mathrm{~cm}^{-1}\left(\mathrm{G}^{-}\right)$. The ratio of $\mathrm{G}^{-} / \mathrm{G}^{+}$ indicates the portion of metallic CNTs. The high peak value of $\mathrm{D}$ to $\mathrm{G}^{-}$suggests a band resonance condition or heavy defect. Each peak of $\mathrm{D}$ was normalized by the $\mathrm{G}^{-}$peak as the Pd-deposited CNTs showed 0.267 of the $\mathrm{D} / \mathrm{G}^{-}$value. By increasing the temperature, the $\mathrm{D} / \mathrm{G}^{-}$signal was remarkably reduced to 0.192 and 0.139 at $300^{\circ} \mathrm{C}$ and $450^{\circ} \mathrm{C}$, respectively. It is worth noting that the increased defect ratio of 0.552 at a high annealing temperature of $600^{\circ} \mathrm{C}$ implies the oxidation of CNTs or damage on the CNT surface. It was found that there exists an optimum heat treating temperature to cure Pd-decorated CNTs, reducing the defect ratio. According to the Raman investigation, the CNT samples were thermally treated at $450^{\circ} \mathrm{C}$ after the DEP process for sensor fabrication, which also significantly reduced the initial sensor resistance of $225 \mathrm{M} \Omega$ to $220 \Omega$. 


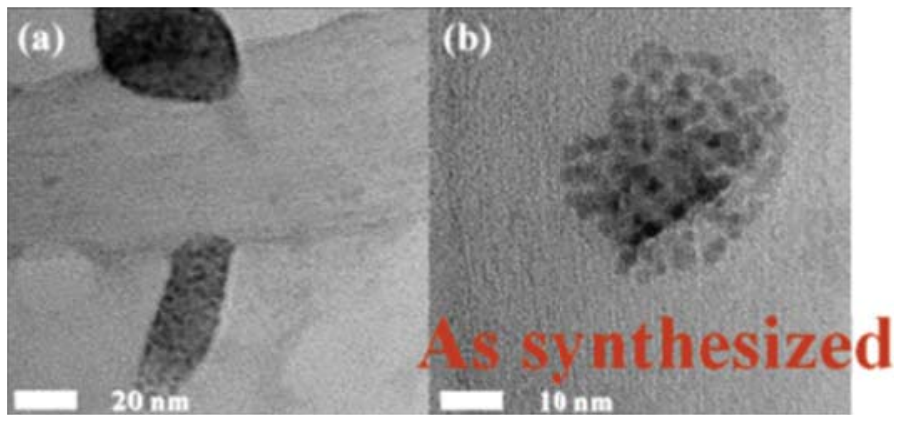

(a)

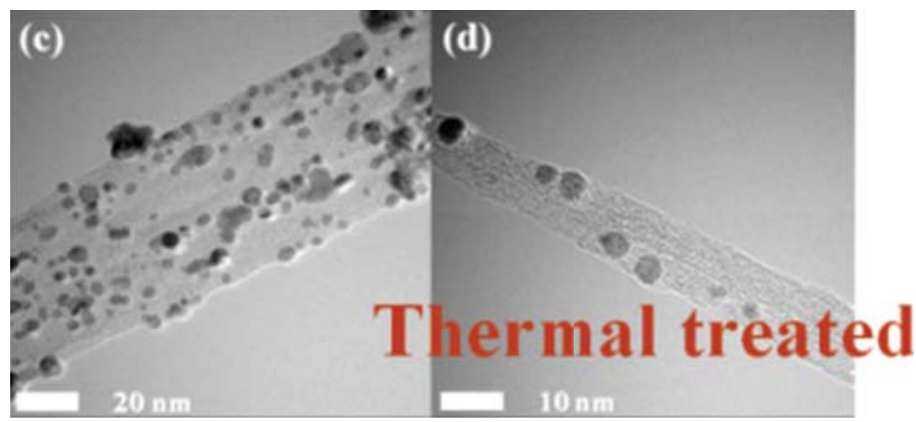

(c) (b)

(d)

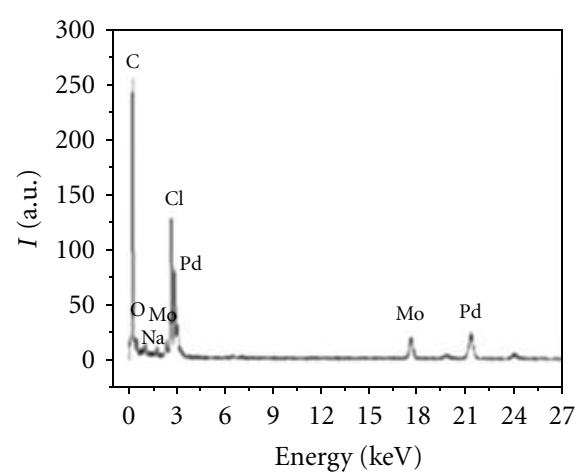

(e)

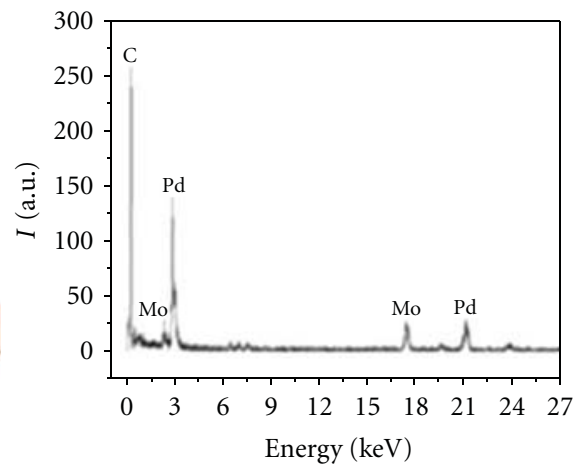

(f)

Figure 8: TEM images of Pd-decorated CNT. (a) and (b) are the as-synthesized case and (c) and (d) are thermally treated case, respectively. EDS analyses of (e) and (f) present the transition of chemical composition by a thermal treatment [24].

TEM images of Pd-CNTs are presented in Figure 8 before and after the thermal annealing. The aggregation of $\mathrm{Pd}$ nanoparticles was observed from the as-synthesized Pd-CNT sample as shown in Figures 8(a) and 8(b). Otherwise, the thermally treated Pd-CNTs at $450^{\circ} \mathrm{C}$ provided the uniformly dispersed $\mathrm{Pd}$ nanoparticles ranging from 3 to $5 \mathrm{~nm}$ in diameter, as shown in Figures 8(c) and 8(d). The EDS analysis was performed to investigate the compositional changes of the Pd-CNTs by thermal treatment. Figure 8(e) depicts the chemical signals of $\mathrm{Pd}$, carbon (C), molybdenum (Mo), and chloride ( $\mathrm{Cl}$ ) as well. The Mo peak and $\mathrm{Cl}$ peak mainly originated from the TEM grid and Pd solution of palladium(II) chloride, respectively. After thermal treating at $450^{\circ} \mathrm{C}$, the $\mathrm{Cl}$ peak was significantly removed, as shown in Figure $8(\mathrm{f})$, which contributed to reducing the sensor contact resistance.

The two types of fabricated bare CNTs and Pd-CNT gas sensors were loaded in a chamber for $\mathrm{NO}_{2}$ gas detection with varying concentration levels of $100 \mathrm{ppb}, 500 \mathrm{ppb}$, and $1 \mathrm{ppm}$. The response time and recovery time were limited to $5 \mathrm{~min}$ and $10 \mathrm{~min}$, respectively. The target gas level was modulated by mixing the filtered clean air with pure $\mathrm{NO}_{2}$ gas $(99.999 \%)$ in a calibrator with an accuracy resolution of $0.1 \%$. The measurement was performed in an atmospheric pressure condition without vacuum system assistance [25] or a gate control [26], which is an important feature in realizing the practical sensor application. The clean air was used as a base gas and purged for $5 \mathrm{~min}$, which stabilized the base measurement condition. During the purging process, there was little change in resistance values, showing the balanced electron-hole transportation in the steady state.

The sensor response (SR) was defined as the ratio of resistance change $\mathrm{SR}=\Delta R / R_{\mathrm{ini}}$, where $\Delta R$ and $R_{\text {ini }}$ represent the resistance change by reacting to $\mathrm{NO}_{2}$ gas and an initial resistance, respectively. The sensor responses were measured at different operating temperatures of room temperature (RT), 88, 145 , and $321^{\circ} \mathrm{C}$ controlled by a ceramic heater with a digital power controller. The temperature was read by a k-type thermocouple. The gas responses from a PdCNT sensor and a bare CNT sensor were presented in Figures 9(a) and 9(b), respectively. During the limited response time of $5 \mathrm{~min}$, the maximum response was found at $88^{\circ} \mathrm{C}$ from the Pd-CNT. For $100 \mathrm{ppb} \mathrm{NO}_{2}$ detection, the sensor gave $0.25 \%$ response at RT without heating but the enhanced response was achieved at $88^{\circ} \mathrm{C}$ to be $3.67 \%$ and $2.79 \%$ from the Pd-CNT sensor and the bare CNT sensor, respectively. By increasing the gas concentration, the responses were proportionally increased. At a fixed heating temperature of $88^{\circ} \mathrm{C}$, the Pd-CNT sensor response was found to be $8.54 \%$ at $500 \mathrm{ppb}$ and $9.91 \%$ at $1 \mathrm{ppm}$, respectively. The enhanced response is attributed to the increase of gas absorption by the heating operation. To investigate the effect of heating temperature, the sensor response was scanned by varying the operating temperature.

At a fixed concentration of $100 \mathrm{ppb}$, the Pd-CNT sensor was more sensitive at $88^{\circ} \mathrm{C}$, giving $3.67 \%$ compared to $3.45 \%$ 


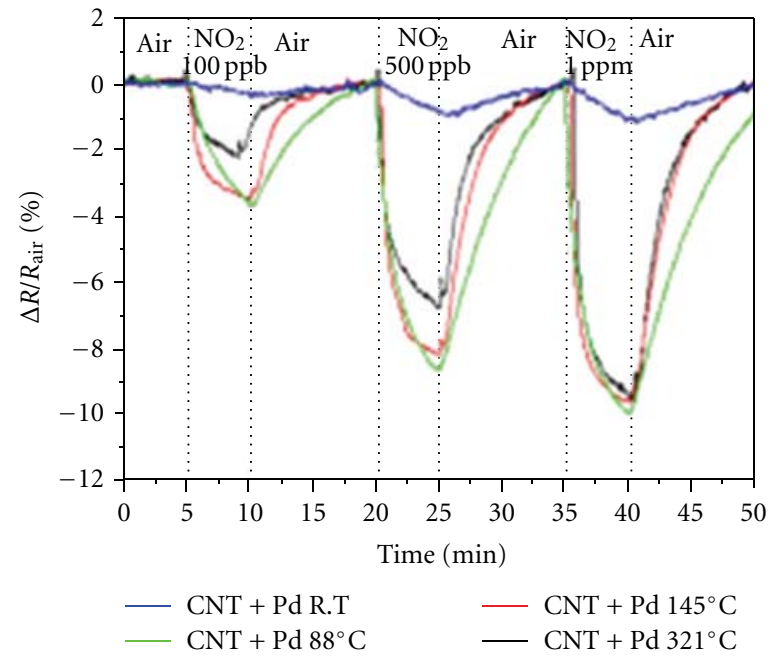

(a)

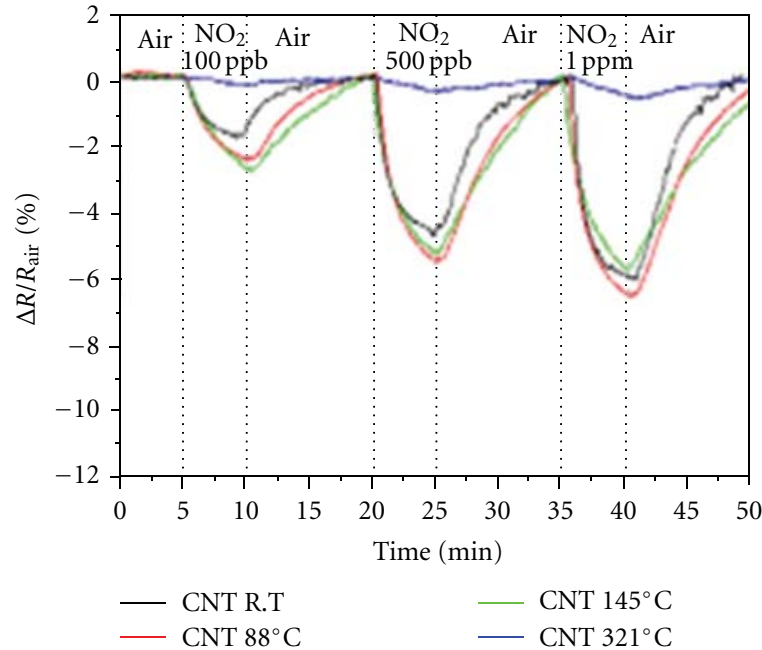

(b)
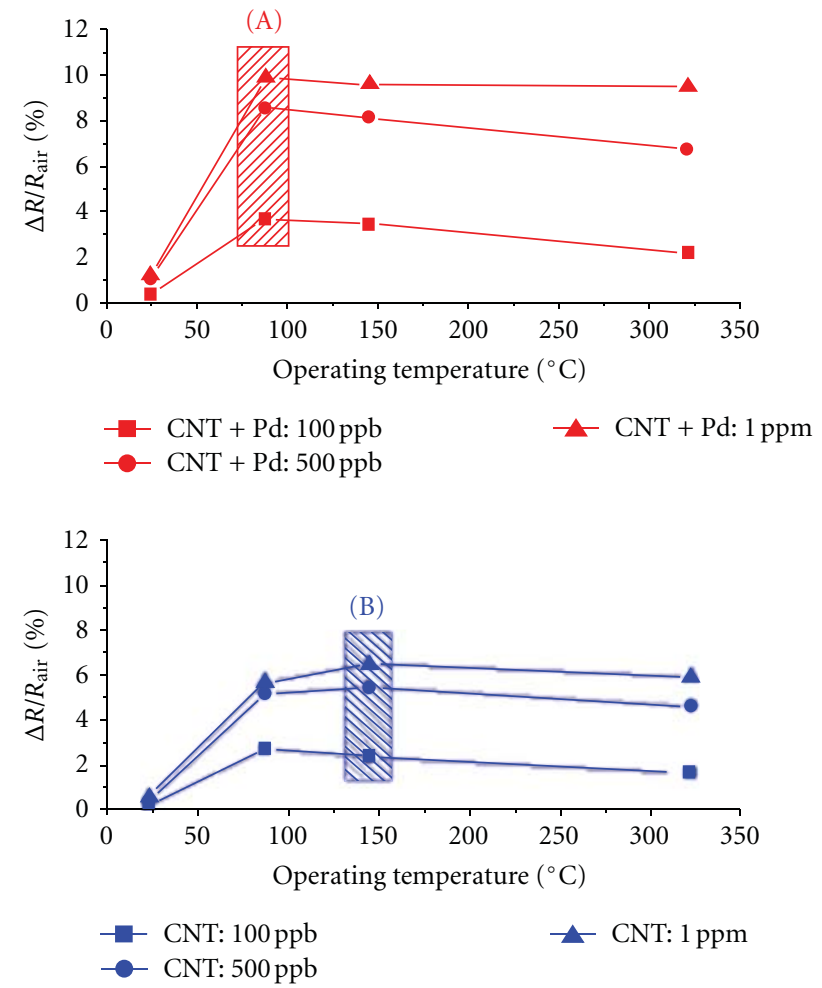

(c)

Figure 9: Sensor responses of (a) Pd-CNTs and (b) bare CNTs. The enhanced responses were achieved from the Pd-CNTs sensor. (c) The heating operation improved the sensor responses. The optimum operating temperatures were reduced by Pd decoration [24].

at $145^{\circ} \mathrm{C}$ or $2.17 \%$ at $321^{\circ} \mathrm{C}$, as presented in Figure $9(\mathrm{c})$. It clearly indicates that there exists an optimum operating temperature. Above the critical temperature, the thermal conductivity of CNTs is decreased due to phonon scattering [28] and accelerates the desorption of gas molecules from the CNTs by lowering the energy barrier, resulting in a decrease of the response $[25,29]$. Otherwise, the bare CNT sensor has a higher optimum operating temperature of $145^{\circ} \mathrm{C}$ with lower sensor response compared to the performance of the
Pd-CNTs. It is considered that the contribution of the Pd nanoparticle decoration on CNTs is quite significant in response to $\mathrm{NO}_{2}$ gas.

Figure 10 presents the sensing mechanism of the PdCNTs sensor. A schematic of the Pd-CNT sensor is illustrated in Figure 10(a). The reaction of Pd decoration spots on CNTs was presented in Figure 10(b). Ideally, each Pd nanoparticle on a CNT forms a Schottky contact localizing the depletion region, which hinders the hole carrier mobility. Moreover, 


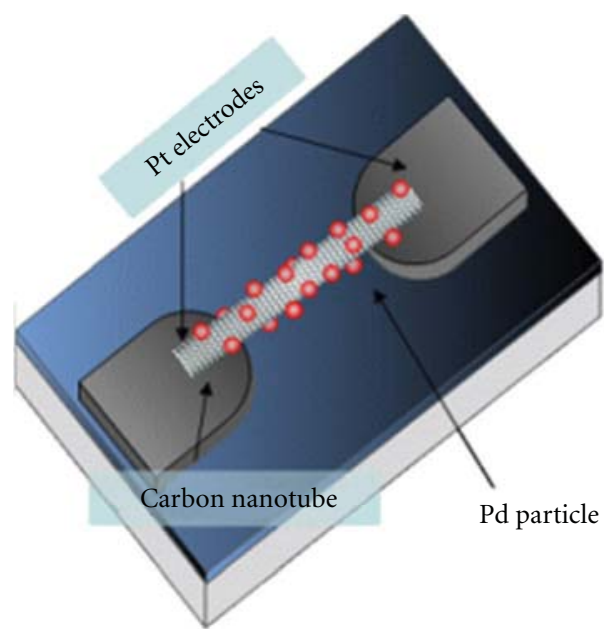

(a)

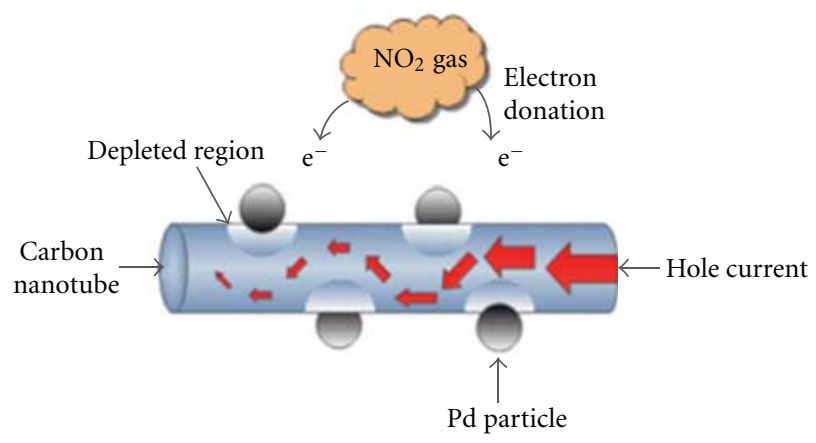

(b)

FIgURE 10: (a) A schematic of the sensor structure of the Pd-decorated CNTs. (b) The enhanced sensing mechanism of Pd-CNTs forming the depletion region by Pd nanoparticles [24].

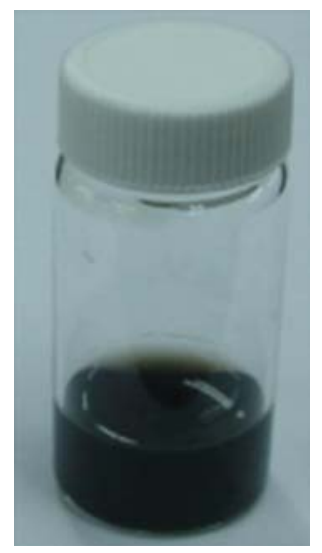

(i) Prepared CNT solution

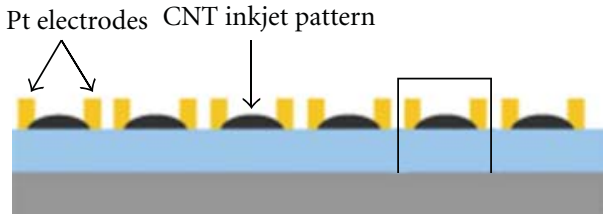

(iii) Metal $(\mathrm{Pt})$ pattering

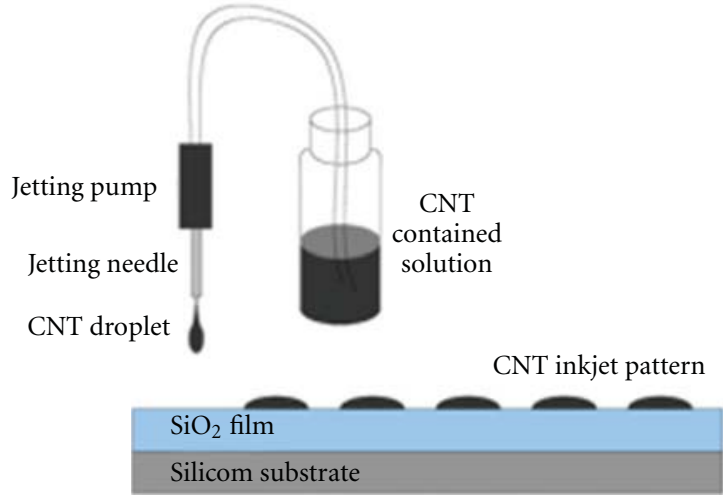

(ii) Ink-jetting

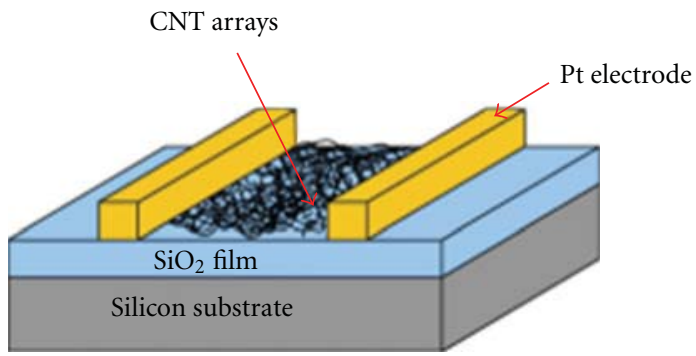

(iv) Slicing and packaging

FIgURE 11: Gas sensor units fabrication steps [27].

the supply of electron carriers by reacting to the oxidizing gas of $\mathrm{NO}_{2}$ causes an increase in electron-hole recombination, causing the lower hole carrier density in a CNT, which raises the effect of localizing depletion regions. This reaction conclusively reduces the hole carrier concentration, which increases the sensor resistance, resulting in enhancing the response of the Pd-CNT sensor. It presents the scheme of a highly sensitive Pd-CNT gas sensor working in an atmospheric pressure condition, which is freed from the assistance of a vacuum system or a gate control, which may 


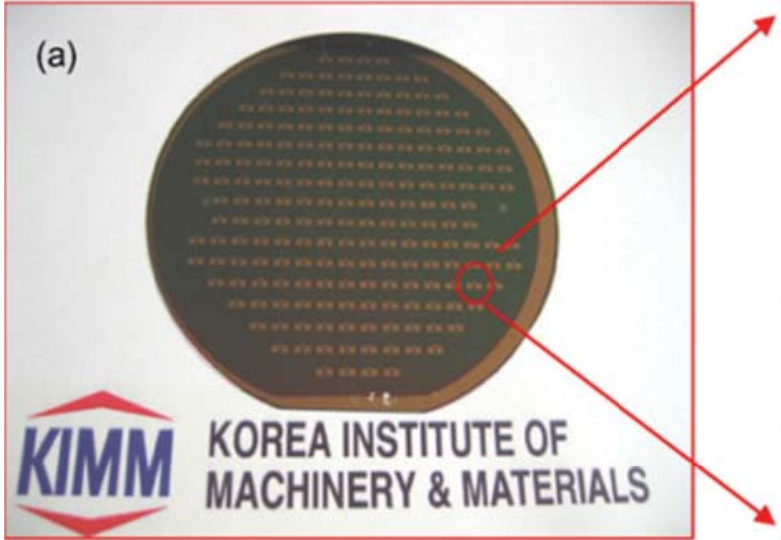

(a)

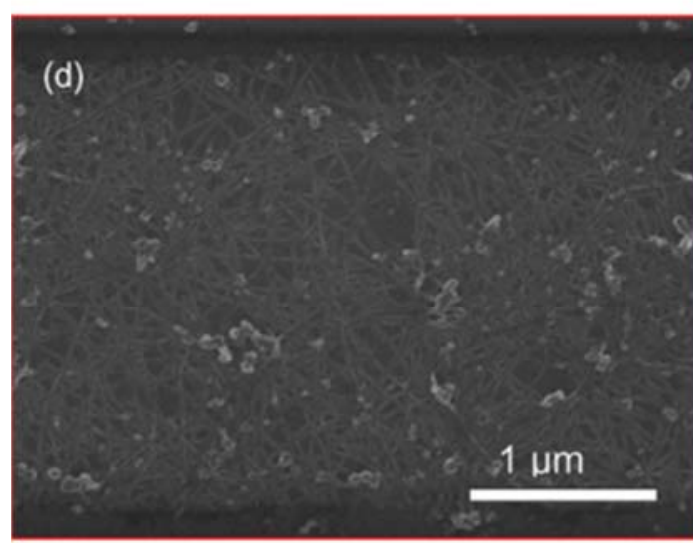

(d)
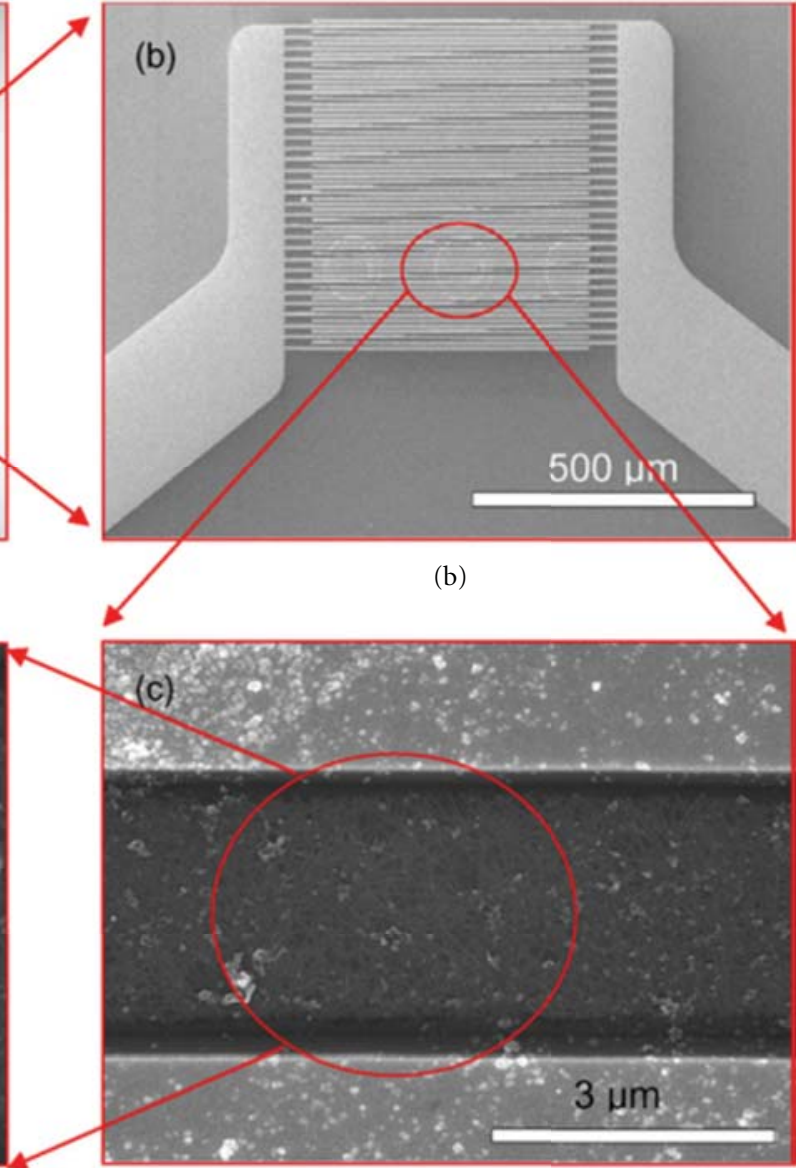

(c)

Figure 12: (a) A photograph image of 200 gas sensor units fabricated on a 4 in. wafer. (b) Interdigitated electrode fingers from a unit device. Enlarged SEM images of circle spots from (b) to (c) and from (c) to (d). CNT arrays clearly underlaid the Pt electrode fingers [27].

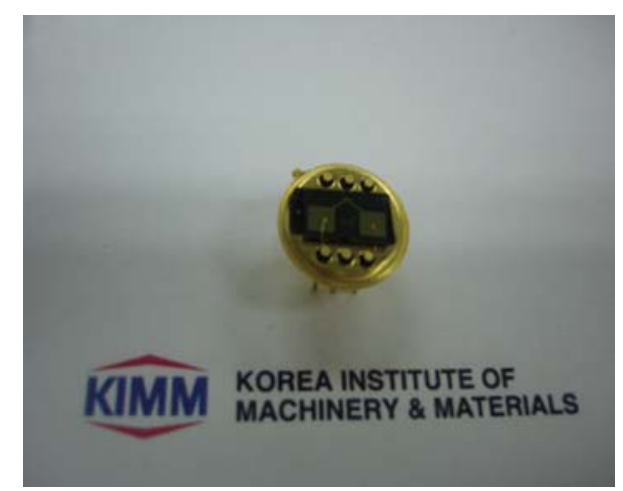

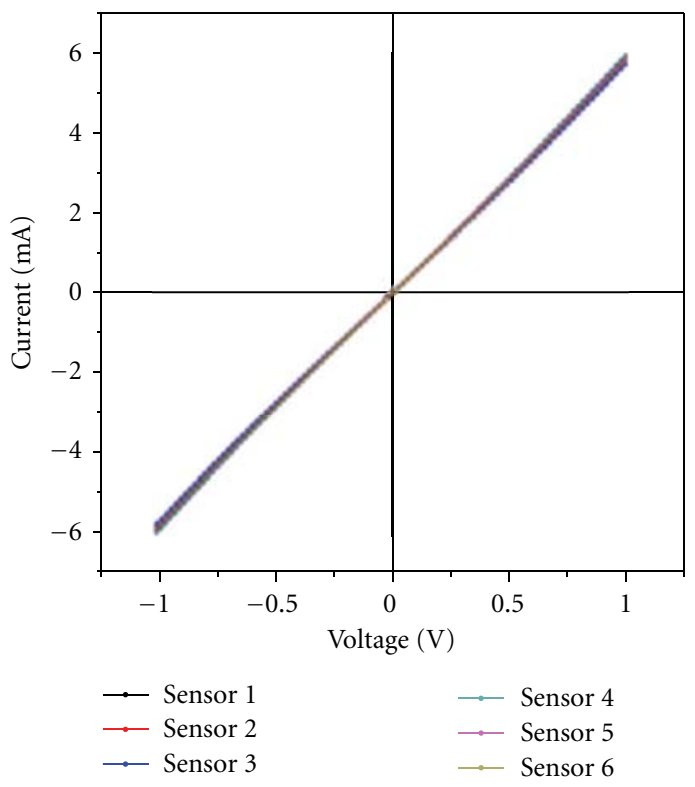

(b)

FIGURE 13: (a) A packed sensor unit. (b) I-V characteristics of the unit sensors [27]. 


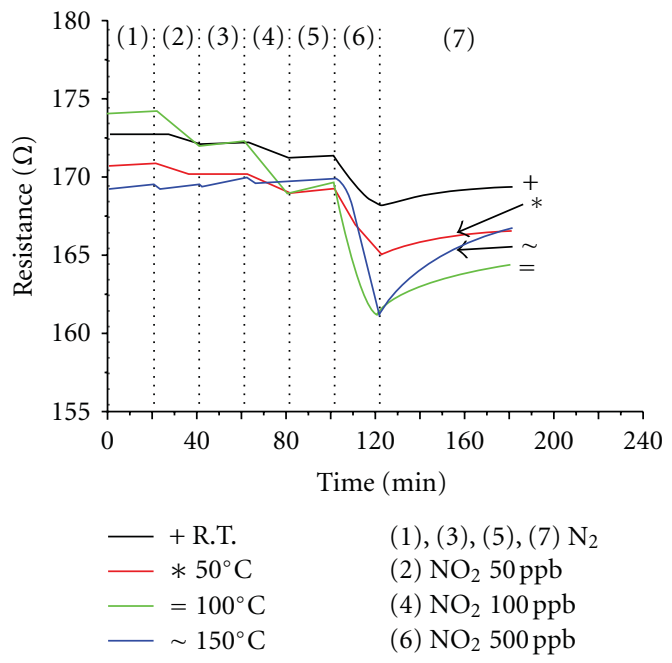

(a)

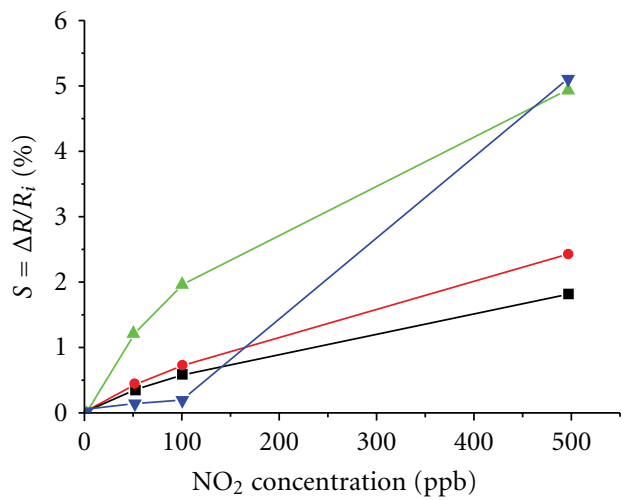

$-\square-$ R.T.

$-\Delta-100^{\circ} \mathrm{C}$

$-\nabla-150^{\circ} \mathrm{C}$

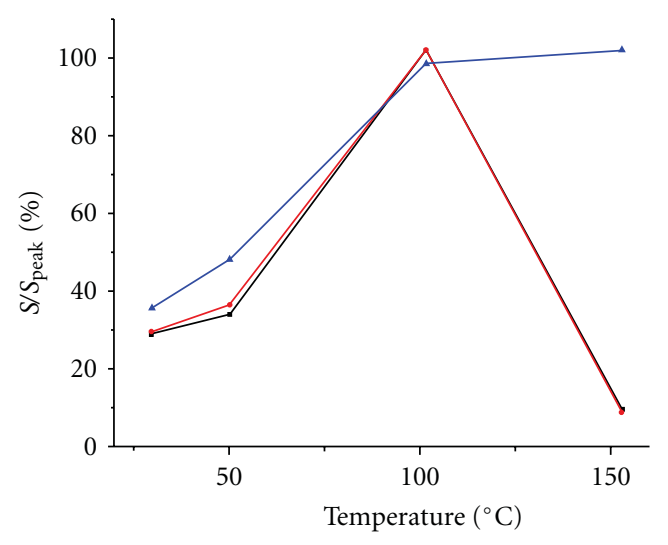

- $\mathrm{NO}_{2} 50 \mathrm{ppb}$

$\because \mathrm{NO}_{2} 100 \mathrm{ppb}$

$\simeq \mathrm{NO}_{2} 500 \mathrm{ppb}$

(c)

Figure 14: (a) The initial resistance values of unit sensors ranged from 172.7 to $169.2 \Omega$. $\mathrm{NO}_{2}$ concentration was varied from 50 to 500 ppb with scanning temperatures. (b) A chart of sensitivity changes by varying temperatures and gas concentrations. (c) A chart of temperature effects on sensitivity by fixing $\mathrm{NO}_{2}$ concentration. The sensitivity values were normalized by the peak sensitivity for different concentrations [27].

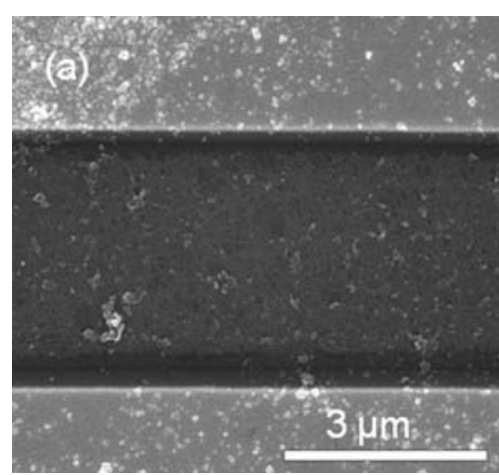

(a)

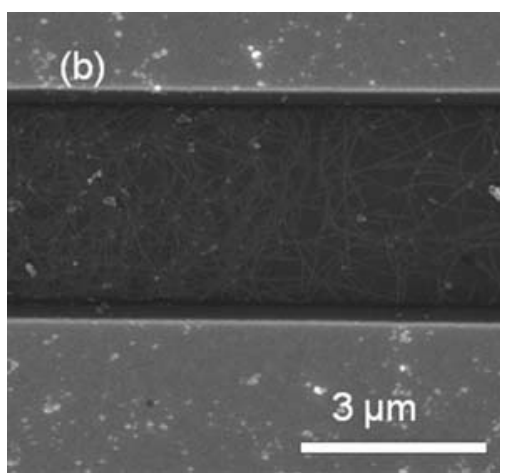

(b)

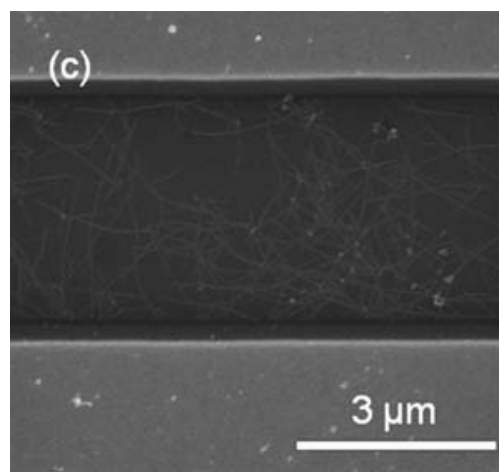

(c)

FIGURE 15: CNT array density was modulated by inkjet printing times. The resistance values were measured to be (a) $170 \Omega$, (b) $315 \Omega$, and (c) $575 \Omega$, respectively [27]. 


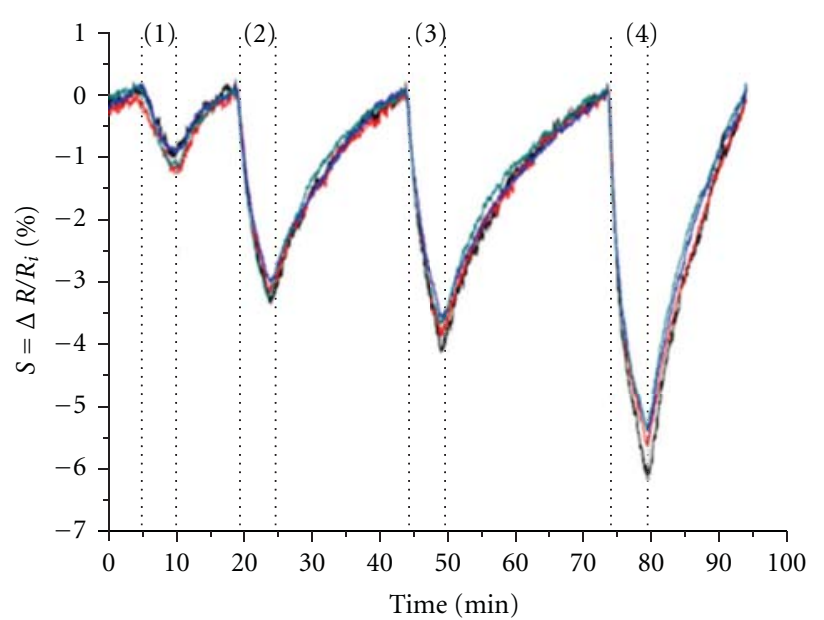
- Sensor 1
(1) $\mathrm{NO}_{2} 10 \mathrm{ppb}$
Sensor 2
(2) $\mathrm{NO}_{2} 50 \mathrm{ppb}$
- Sensor 3
(3) $\mathrm{NO}_{2} 100 \mathrm{ppb}$
- Sensor 4
(4) $\mathrm{NO}_{2} 300 \mathrm{ppb}$

FIGURE 16: The thinner CNT array density response to $\mathrm{NO}_{2}$ gas, which has resistances of 570-590 $\Omega$. The enhanced active area of $\mathrm{CNT}$ arrays improved the sensitivity and detected $10 \mathrm{ppb}$ level of $\mathrm{NO}_{2}$ [27].

provide advantages in sensor fabrication steps and practical applications.

\subsection{Inkjet Method}

3.3.1. Gas Sensor Fabrication Steps. The location of nanomaterial at designated positions is an essential process to fabricate nanoscale-structure-embedded systems. Inkjet method was applied to deposit the CNT arrays on a 4 in. wafer. The gas sensor unit fabrication was prepared by following steps: (i) preparing the CNT-contained solution, (ii) inkjetting the CNT-contained solution on an Si wafer, (iii) metal (Pt) pattering on the deposited CNT arrays, and (iv) slicing and packaging a sensor unit. The steps are illustrated in Figure 11. In preparation of CNT-contained solution, commercial CNTs (Iljin nanotech, ASP-100) were dispersed in DMF (dimethylformamide) dispersant to debundle and stabilize the CNT dispersion in solution and then centrifuged for $30 \mathrm{~min}$ to remove residuals. The solution concentration of $20 \mu \mathrm{g} / \mathrm{mL}$ was deposited on a $4 \mathrm{in}$. Si wafer according to the align references. Metal contacts $(\mathrm{Pt})$ were interdigitally formed on the deposited CNT arrays by conventional metal lift-off processes, which provide the spontaneous metalsitting structure above CNT arrays.

The 200-gas sensor units fabricated on a 4 in. wafer are shown in Figure 12(a). The scanning electron microscopy (SEM) images of a single sensor unit and interdigitated electrodes were shown 12 (b) and 12(c), respectively. Figure 12(d) presents the uniformly distributed CNT arrays under electrodes. Interdigitated electrode has a gap of $3 \mu \mathrm{m}$, where is the CNT active region to response to gas species. As shown clearly, CNT arrays are underlaid the Pt electrode fingers, which ensure the response is derived from the CNTs instead of metal contacts. The electrode metal of Pt has a higherwork function $(5.65 \mathrm{eV})$ than that of CNT $(4.9 \mathrm{eV})$, which derives the Ohmic contact formation [30].

3.3.2. Packed Units. Figure 13(a) is an image of the packed unit sensor. Figure 13(b) shows that the electrical measurements of unit devices randomly picked from slicing a wafer. The resistance values are uniformly low (169.3-176 $\Omega$ ) due to the structural benefit of metal-sitting on CNT arrays. An attractive contact architecture of metal-sitting structure provides physically and electrically solid contacts without the posttreatment, such as focused-ion-beam (FIB) assisted metal deposition, which may cause noisy contact resistances [31].

3.3.3. Responses to $\mathrm{NO}_{2}$ Gas. Figure 14(a) shows the sensor responses to $\mathrm{NO}_{2}$ gas. For gas sensing, the sensor was loaded in a chamber and then $\mathrm{N}_{2}$ purged for $10 \mathrm{~min}$ to stabilize a base measurement line. The gas responses were performed at different temperature settings by room temperature (RT), 50, 100 , and $150^{\circ} \mathrm{C}$. The sensing measurements were performed for $10 \mathrm{~min}$ exposure to gas followed by a $10 \mathrm{~min}$ recovery period for three times. It showed that the gas sensor is sensitive to $\mathrm{NO}_{2}$ gas exposure and revealed the changes of sensitivity by temperature modulation. $50 \mathrm{ppb}$ level of $\mathrm{NO}_{2}$ were detected at RT, 50 , and $100^{\circ} \mathrm{C}$. Interestingly, however, no significant change was found from $150^{\circ} \mathrm{C}$ case. The sensitivity $\left(S=\Delta R / R_{i}\right)$ is defined as the ratio of resistance changes $(\Delta R)$ by reacting to $\mathrm{NO}_{2}$ versus the initial resistance value $\left(R_{i}\right)$ and was shown in Figure 14(b). Figure 14(c) shows the sensitivity chart by varying temperature at a fixed gas concentration. It clearly presents the tendency of sensitivity changes by heating temperatures. By increasing temperature, the reaction between gas molecules to CNTs is facilitated. However, beyond a critical temperature, the thermal conductivity of CNT is decreased due to the phonon scattering [31] and accelerates the desorption of gas molecules from the CNT with lowering energy barrier resulting in decreasing of sensitivity [32]. The metal-sitting architecture has an advantage to prevent the modification of Schottky barrier modulation by adsorbed gas molecules [33] and ensures the responses to gas molecules come from the active entity of CNT arrays.

3.3.4. CNT Density Modification. Due to the benefit of inkjet printing method, the density of CNT arrays would be modulated resulting in control of resistances as shown in Figure 15. The sensors having a thinner dense CNT arrays were fabricated, which have resistance of 570-590 $\Omega$. Figure 16 showed that the detection level of sensors was reached to $10 \mathrm{ppb} \mathrm{NO}_{2}$ with uniform performances at room temperature and atmospheric pressure not at vacuum condition $[34,35]$. The sensitivity was obtained to be $5.73 \%$ for $100 \mathrm{ppb} \mathrm{NO}_{2}$, which showed the higher response than that of $0.58 \%$ from the sensor having a resistance of $170 \Omega$ at room temperature as presented in Figure 14. The improved detecting performance of thinner density case is attributed to the enhanced active area of CNT array by being effectively exposed to gas molecules with less inactive CNT entities resulting from overlapping one to others. Detecting a target 


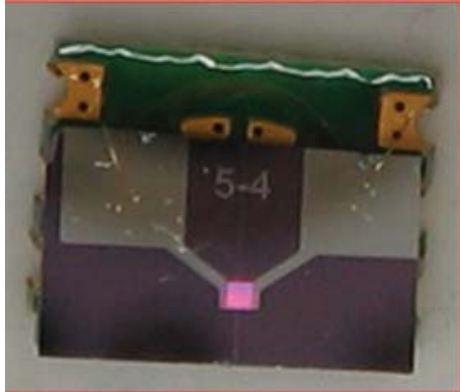

(a)

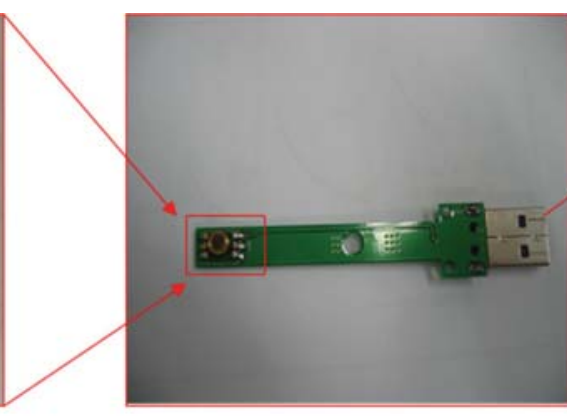

(b)

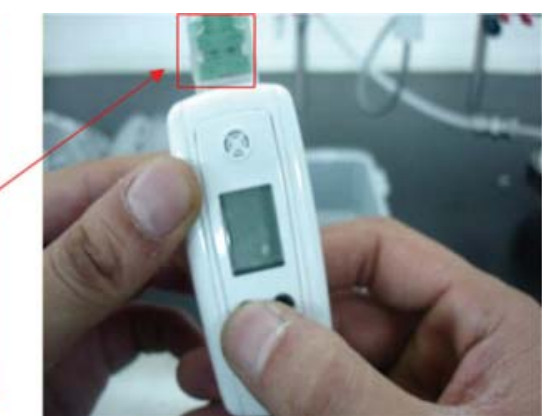

(c)

FIgURE 17: (a) A single sensor unit, (b) A sensor unit equipped USB, (c) A sensor kit.

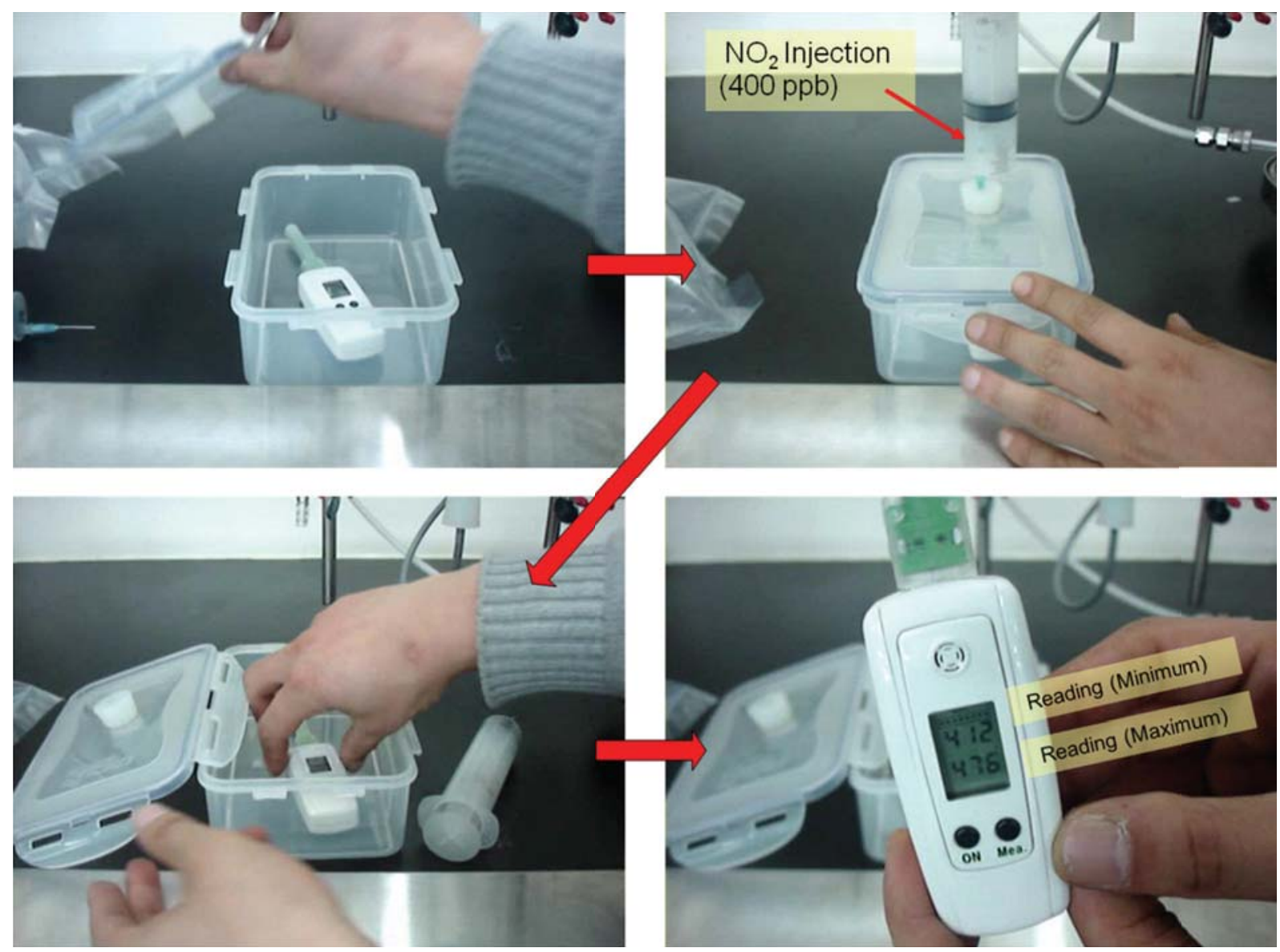

FIgURE 18: Demonstration of the CNT gas sensor kit. The CNT sensor indicates an $\mathrm{NO}_{2}$ reading of $412 \mathrm{ppb}$.

gas at the atmospheric condition is a merit in sensor operation and fabrication as well by simplifying the structures. It implies that the controlling exposing surface area of CNT arrays may enhance the reaction to gas molecules to improve sensitivity without a heating or a vacuum equipment. All the samples responded similarly at each gas concentration, which is a strong proof of the uniform fabrication of sensor by inkjet printing method.

3.3.5. CNT Sensor Kit. Inkjet-printed CNT sensor units were fabricated as a portable sensor kit. A single sensor unit was
Au-wired on a printed circuit board (PCB) as shown in Figures 17 (a) and 17(b). A sensor module has a universal serial bus (USB) port to show its reading value on the display, as shown in Figure 17(c). The sensor module has a rechargeable Li-ion battery. The wafer-scale fabricated CNT unit cells were tested for uniformity to $\mathrm{NO}_{2}$ gas response. The resistance change according to the $\mathrm{NO}_{2}$ gas concentration was previously programmed according to the $\mathrm{NO}_{2}$ gas concentration. Figure 18 shows the setup of the demonstration test. A CNT gas sensor kit was placed in a test box and then a 400 ppb quantity of $\mathrm{NO}_{2}$ was injected into the 
box. After the gas response, the sensor kit indicated $412 \mathrm{ppb}$ (minimum) value.

3.3.6. Development Prospects. A two terminal device detects the change of resistance due to exposure to the target gas. This structure has the advantage of easy fabrication. As previously discussed, the sensing performance can be substantially enhanced by modulating the operating voltage, heating condition, and functional decoration in the CNT entities. Having a three-device for a transistor would improve the CNT sensor performance, especially in terms of producing a significant reduction in recovery time [36] by means of a gate signal. The CNT has advantages for use as a high sensitive gas sensor that will be available to implantation in a compact package. However, pristine CNTs have certain limits due to their lack of selectivity and long recovery time [16]. To resolve these problems, functionalized CNTs have been proposed and intensively investigated. These functionalized CNTs can be tuned to the binding energy [37] in order to modulate the dynamic response of CNT sensors, leading to a high potential for use in selective gas detection with a quick response.

\section{Conclusions}

Two types of CNT sensors were fabricated with bare CNTs and Pd-decorated CNTs. The dielectrophoresis method was applied to align the CNTs between the Pt electrodes. Raman spectroscopy revealed that postheat treatment at $450^{\circ} \mathrm{C}$ was effective in reducing the chemical residuals, giving a low defect ratio of $\mathrm{D} / \mathrm{G}^{-}$in the $\mathrm{Pd}-\mathrm{CNT}$ composition. It has been proved that the localized depletion region formed by $\mathrm{Pd}$ nanoparticles on the CNTs significantly improves the sensor reaction at atmospheric pressure conditions by control of the carrier transportation.

Inkjet printing method was used to demonstrate the reliable mass production of highly sensitive CNT-based gas sensors by producing 200 sensor units on a 4 -inch wafer. Inkjet method was adopted to control the deposition of carbon nanotubes at designated positions via the modulation of density of CNT arrays. Direct metal patterning above the CNT arrays provide simple and stable contact formation between metal and CNT arrays. The performances of the sensors were uniform and highly sensitive; they were sufficiently sensitive to detect a $10 \mathrm{ppb}$ level of $\mathrm{NO}_{2}$.

Although CNTs are potential materials for use in high sensitive gas sensor applications, their promise has not yet been fulfilled in terms of commercialization, mainly due to the lack of selectivity and repeatability. Commercial success may be attained in the near future by developing high functioning CNTs and an effectively combined sensing mechanism.

\section{Acknowledgment}

The author acknowledges the financial support of the Korea Institute of Energy Technology Evaluation and Planning (KETEP-20113030010110). Some parts of this paper were reported from the author's previous reports.

\section{References}

[1] M. I. Shakir, M. Nadeem, S. A. Shahi, and N. M. Mohamed, "Carbon nanotube electric field emitters and applications," Nanotechnology, vol. 17, pp. R41-R56, 2006.

[2] J. Kim, E. S. Lee, C. S. Han, Y. Kang, D. Kim, and W. A. Anderson, "Observation of Ni silicide formations and field emission properties of Ni silicide nanowires," Microelectronic Engineering, vol. 85, no. 8, pp. 1709-1712, 2008.

[3] B. Zeng, G. Xiong, S. Chen, W. Wang, D. Z. Wang, and Z. F. Ren, "Field emission of silicon nanowires grown on carbon cloth," Applied Physics Letters, vol. 90, no. 3, Article ID 033112, 3 pages, 2007.

[4] G. N. Fursey, "Field emission in vacuum micro-electronics," Applied Surface Science, vol. 215, no. 1-4, pp. 113-134, 2003.

[5] J. Kim, D. H. Kim, E.-S. Lee, C.-S. Han, and Y. C. Park, "Electrical characteristics of single and doubly connected Ni silicide nanowire grown by plasma-enhanced chemical vapor deposition," Applied Physics Letters, vol. 90, no. 25, Article ID 253103, 3 pages, 2007.

[6] J. Kim and W. A. Anderson, "Direct electrical measurement of the self-assembled nickel suicide nanowire," Nano Letters, vol. 6, no. 7, pp. 1356-1359, 2006.

[7] J. H. Lee, J. Kim, H. W. Seo et al., "Bias modulated highly sensitive $\mathrm{NO}_{2}$ gas detection using carbon nanotubes," Sensors and Actuators B, vol. 129, no. 2, pp. 628-631, 2008.

[8] J.-W. Song, J. Kim, Y.-H. Yoon, B.-S. Choi, J.-H. Kim, and C.-S. Han, "Inkjet printing of single-walled carbon nanotubes and electrical characterization of the line pattern," Nanotechnology, vol. 19, no. 9, Article ID 095702, 2008.

[9] A. S. Shamaev and V. A. Samarin, "On propagation of acoustic waves in the medium consisting of a fluid and an elastic material," Journal of Mathematical Sciences, vol. 144, no. 4, pp. 4284-4291, 2007.

[10] C. Cantalini, L. Valentini, I. Armentano, J. M. Kenny, L. Lozzi, and S. Santucci, "Carbon nanotubes as new materials for gas sensing applications," Journal of the European Ceramic Society, vol. 24, no. 6, pp. 1405-1408, 2004.

[11] J. Kong, N. R. Franklin, C. Zhou et al., "Nanotube molecular wires as chemical sensors," Science, vol. 287, no. 5453, pp. 622$625,2000$.

[12] A. Fujiwara, K. Ishii, H. Suematsu et al., "Gas adsorption in the inside and outside of single-walled carbon nanotubes," Chemical Physics Letters, vol. 336, no. 3-4, pp. 205-211, 2001.

[13] C. Marliere, P. Poncharal, L. Vaccarini, and A. Zahab, "Effect of gas adsorption on the electrical properties of single walled carbon nanotubes mats," Materials Research Society Symposium Proceedings, vol. 593, pp. 173-177, 2000.

[14] Y. Wang and T. W. Yeow, "A review of carbon nanotubes-based gas sensors," Journal of Sensors, vol. 2009, Article ID 493904, 24 pages, 2009.

[15] Y. Hu and C. Guo, Carbon Nanotubes-Growth and Applications, InTech, Vienna, Austria, 2011.

[16] T. Zhang, S. Mubeen, N. V. Myung, and M. A. Deshusses, "Recent progress in carbon nanotube-based gas sensors," Nanotechnology, vol. 19, no. 33, Article ID 332001, 2008.

[17] Z. Zanolli, R. Leghrib, A. Felten, J. J. Pireaux, E. Llobet, and J. C. Charlier, "Gas sensing with au-decorated carbon nanotubes," ACS Nano, vol. 5, no. 6, pp. 4592-4599, 2011.

[18] C. E. Cava, R. V. Salvatierra, D. C. B. Alves, A. S. Ferlauto, A. J. G. Zarbin, and L. S. Roman, "Self-assembled films of multi-wall carbon nanotubes used in gas sensors to increase the sensitivity limit for oxygen detection," Carbon, vol. 50, no. 5, pp. 1953-1958, 2012. 
[19] J. Li, Y. Lu, Q. Ye, M. Cinke, J. Han, and M. Meyyappan, "Carbon nanotube sensors for gas and organic vapor detection," Nano Letters, vol. 3, no. 7, pp. 929-933, 2003.

[20] H. Y. Jung, S. M. Jung, J. R. Kim, and J. S. Suh, "Chemical sensors for sensing gas adsorbed on the inner surface of carbon nanotube channels," Applied Physics Letters, vol. 90, no. 15, Article ID 153114, 3 pages, 2007.

[21] W. D. Zhang, "Growth of $\mathrm{ZnO}$ nanowires on modified wellaligned carbon nanotube arrays," Nanotechnology, vol. 17, no. 4, pp. 1036-1040, 2006.

[22] B. Jia, L. Gao, and J. Sun, "Self-assembly of magnetite beads along multiwalled carbon nanotubes via a simple hydrothermal process," Carbon, vol. 45, no. 7, pp. 1476-1481, 2007.

[23] L. Dong, J. Bush, V. Chirayos et al., "Dielectrophoretically controlled fabrication of single-crystal nickel silicide nanowire interconnects," Nano Letters, vol. 5, no. 10, pp. 2112-2115, 2005.

[24] J.-H. Yun, J. Kim, Y. C. Park, J.-W. Song, D.-H. Shin, and C.S. Han, "Highly sensitive carbon nanotube-embedding gas sensors operating at atmospheric pressure," Nanotechnology, vol. 20, no. 5, Article ID 055503, 2009.

[25] Y. D. Lee, W.-S. Cho, S.-I. Moon et al., "Gas sensing properties of printed multiwalled carbon nanotubes using the field emission effect," Chemical Physics Letters, vol. 433, no. 1-3, pp. 105-109, 2006.

[26] O. Kuzmych, B. L. Allen, and A. Star, "Carbon nanotube sensors for exhaled breath components," Nanotechnology, vol. 18, no. 37, Article ID 375502, 2007.

[27] J. Kim, J. H. Yun, J. W. Song, and C. S. Han, “The spontaneous metal-sitting structure on carbon nanotube arrays positioned by inkjet printing for wafer-scale production of high sensitive gas sensor units," Sensors and Actuators B, vol. 135, no. 2, pp. 587-591, 2009.

[28] M. Fujii, X. Zhang, H. Xie et al., "Measuring the thermal conductivity of a single carbon nanotube," Physical Review Letters, vol. 95, no. 6, Article ID 065502, 4 pages, 2005.

[29] W. Wongwiriyapan, S. Honda, H. Konishi et al., "Singlewalled carbon nanotube thin-film sensor for ultrasensitive gas detection," Japanese Journal of Applied Physics, vol. 44, pp. L482-L484, 2005.

[30] H. M. Manohara, E. W. Wong, E. Schlecht, B. D. Hunt, and P. H. Siegel, "Carbon nanotube schottky diodes using TiSchottky and Pt-Ohmic contacts for high frequency applications," Nano Letters, vol. 5, no. 7, pp. 1469-1474, 2005.

[31] F. Hernández-Ramírez, A. Tarancón, O. Casals, J. Arbiol, A. Romano-Rodríguez, and J. R. Morante, "High response and stability in $\mathrm{CO}$ and humidity measures using a single $\mathrm{SnO}_{2}$ nanowire," Sensors and Actuators B, vol. 121, no. 1, pp. 3-17, 2007.

[32] M. Fujii, X. Zhang, H. Xie et al., "Measuring the thermal conductivity of a single carbon nanotube," Physical Review Letters, vol. 95, no. 6, Article ID 065502, pp. 1-4, 2005.

[33] K. Bradley, J.-C. P. Gabriel, A. Star, and G. Gruner, "Shortchannel effects in contact-passivated nanotube chemical sensors," Applied Physics Letters, vol. 83, no. 18, pp. 3821-3823, 2003.

[34] Y. W. Chang, J. S. Oh, S. H. Yoo, H. H. Choi, and K.-H. Yoo, "Electrically refreshable carbon-nanotube-based gas sensors," Nanotechnology, vol. 18, no. 43, Article ID 435504, 2007.

[35] J. Chung, K. H. Lee, J. Lee, D. Troya, and G. C. Schatz, "Multiwalled carbon nanotubes experiencing electrical breakdown as gas sensors," Nanotechnology, vol. 15, no. 11, pp. 1596-1602, 2004.
[36] T. Someya, J. Small, P. Kim, C. Nuckolls, and J. T. Yardley, "Alcohol vapor sensors based on single-walled carbon nanotube field effect transistors," Nano Letters, vol. 3, no. 7, pp. 877-881, 2003.

[37] P. C. P. Watts, N. Mureau, Z. Tang, Y. Miyajima, J. David Carey, and S. R. P. Silva, "The importance of oxygen-containing defects on carbon nanotubes for the detection of polar and non-polar vapours through hydrogen bond formation," Nanotechnology, vol. 18, no. 17, Article ID 175701, 2007. 

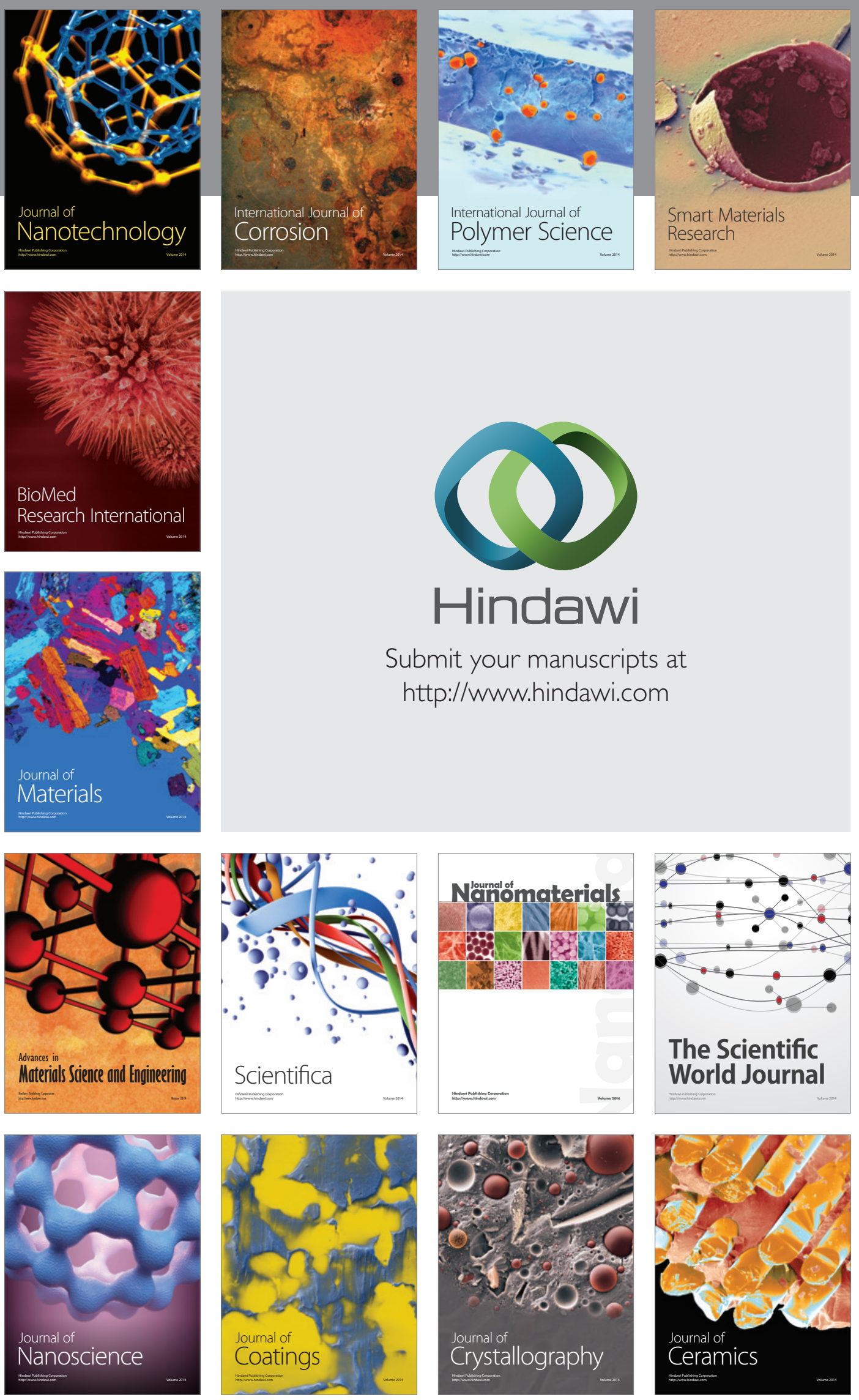

The Scientific World Journal

Submit your manuscripts at

http://www.hindawi.com

\section{World Journal}

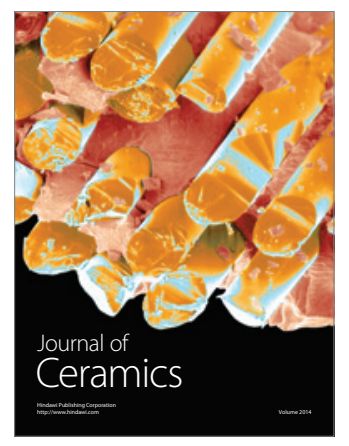

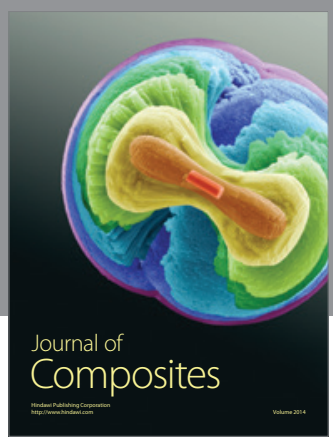
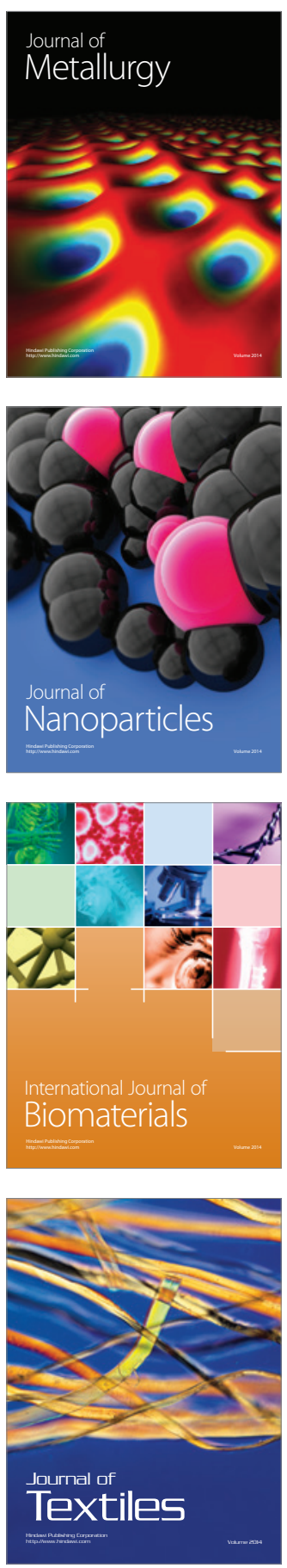